\title{
Production of Murine Monoclonal Antibodies to the Major Axial Filament Polypeptide of Treponema pallidum
}

\author{
By M. J. BAILEY,* A. COCKAYNE AND C. W. PENN \\ Department of Microbiology, University of Birmingham, Birmingham B15 2TT, UK
}

(Received 21 November 1986; revised 29 January 1987)

\begin{abstract}
A suitable immunization protocol for the stimulation of a murine antibody response to the axial filament polypeptides of Treponema pallidum was established. A range of monoclonal antibodies (Mabs) specific for different epitopes of the major axial filament polypeptide $(37 \mathrm{kDa})$ was generated which demonstrated diversity in their ability to react with other treponemal species. Immunogold electron microscopy located the $37 \mathrm{kDa}$ antigen on the surface of the axial filament structure. The early appearance of specific antibody to this polypeptide in infected man and rabbit indicates that such Mabs are potentially useful for the diagnosis of early syphilis.
\end{abstract}

\section{INTRODUCTION}

Penn et al. (1985a) recently defined the antigenic components of the axial filament structure of Treponema pallidum (Nichols strain), showing it to be composed of a major polypeptide $(37 \mathrm{kDa})$ and three minor components $(34,33.5$ and $31.5 \mathrm{kDa})$. There has been considerable interest in the antigens of this structure, and diagnostic tests based on the cross-reactive axial filaments of Treponema phagedenis (biotype Reiterii) have been described (Nell \& Hardy, 1978; Strandberg-Pedersen et al., 1982). The similarity between the axial filaments of the cultivable Reiter treponeme ( $T$. phagedenis) and $T$. pallidum is well established (Strandberg-Pedersen et al., 1981 ; Bharrier \& Allis, 1974). Indeed, a small-scale protection study of rabbits immunized with fractionated Reiter treponeme axial filaments has been described (Hindersson et al., 1985) and although the immunized rabbits produced antibody strongly reactive with the minor components of $T$. pallidum axial filaments, no protection from infection was observed. These findings were predictable as the axial filaments of $T$. pallidum are located within the periplasmic space and covered by an outer membrane. Therefore, those polypeptides which comprise the endoflagella are not exposed at the surface of the intact organism and would not be expected to elicit neutralizing antibody.

Penn et al. (1985a) demonstrated that antibody to the major axial filament polypeptide $(37 \mathrm{kDa})$ could be detected in the extraction medium used to isolate treponemes from infected testes, suggesting the early recognition of this antigen by the immune system. Further immunological investigations into the development of the humoral response in experimental and human syphilis (Lukehart et al., 1982; Hanff et al., 1982, 1983; Bailey et al., 1987) by Western blotting of sera (Penn et al., 1986) have clearly shown the presence of specific antibody to an antigen of approximately $37 \mathrm{kDa}$ early in infection; comparison of these findings with SDS-PAGE profiles of solubilized $T$. pallidum generated in our laboratory indicates that one of the main antigens recognized is this major axial filament polypeptide. Such observations suggest the utility of identification of antibody to this polypeptide in syphilitic sera as a basis for the development of an immunodiagnostic assay.

Abbreviations: hRSS, hyperimmune rabbit syphilitic sera; i.p., intraperitoneal(ly); Mab, monoclonal antibody; NCM, nitrocellulose membrane(s); PAT, PBS containing $0.1 \%$ BSA and $0.1 \%$ Tween $20 ;$ PBS, $7.2 \mathrm{mM}$ $\mathrm{Na}_{2} \mathrm{HPO}_{4}, 2.8 \mathrm{~mm}-\mathrm{NaH}_{2} \mathrm{PO}_{4}, 0.15 \mathrm{M}-\mathrm{NaCl}, \mathrm{pH} 7.2$. 
In order to identify unequivocally the component antigens of the axial filament, monoclonal antibodies (Mabs) to this structure were generated. We have observed that mice respond poorly to the axial filament components after conventional immunization protocols with whole treponemes, and now describe the generation of good responses in mice and the derivation of the requisite Mabs.

\section{METHODS}

Bacterial strains. The Nichols strain of Treponema pallidum was propagated in the testes of Dutch rabbits and purified as previously described (Penn, 1981, 1983; Penn \& Rhodes, 1982). Treponema phagedenis (biotype Reiterii) was cultivated in vitro as described by Penn \& Rhodes (1982). Treponema hyodysenteriae was kindly supplied as a frozen pellet by Dr R. M. Lemcke (IRAD, Compton, Newbury, Berks., UK).

Antigen preparation. Axial filaments were extracted from $T$. pallidum by the method of Penn et al. (1985a).

Immunization. Balb/c female mice (6-8 weeks old) were immunized with a variety of antigen preparations (Table 1) in order to stimulate a response to the axial filament components. Such mice were used either as a source of spleen cells for the production of hybridoma cell lines, or as a supply of specific mouse anti-T. pallidum sera. Hyperimmune mouse sera were generated by the intraperitoneal injection of a $0.1 \mathrm{ml}$ volume containing $10^{8}$ thrice-PBS-washed azide-killed $T$. pallidum cells included in Freund's complete adjuvant (Sigma) on day 0 , subsequently given booster injections on days 14,28 and 56 with the same quantity of bacteria included in Freund's incomplete adjuvant. Mice were also immunized by the intraperitoneal (i.p.) injection of $10^{8}$ live, freshly harvested treponemes in PBS on days 0, 14, 28 and 56. Test bleeds were done $10 \mathrm{~d}$ after the last injection and sera were analysed by Western blotting for the presence of specific antibody. Selected mice were then given further booster injections or new mice were immunized under the regime described above by injecting $0.1 \mathrm{ml}$ purified axial filaments $(0.1 \mathrm{mg})$ included in an equal volume of adjuvant (complete for new mice, incomplete for boosted mice), of which $0.1 \mathrm{ml}$ was injected i.p. Fusions were done on immunized mice which had been given intravenous booster injections of $50 \mu \mathrm{l}$ sonicated purified axial filament in PBS $\left(1 \mathrm{mg} \mathrm{m}^{-1}\right) 10-12 \mathrm{~d}$ after their last i.p. injection and $4 \mathrm{~d}$ before fusion.

Additionally, mice were immunized with a preparation of the $37 \mathrm{kDa}$ polypeptide. After $11 \%$ SDS-PAGE electrophoresis (Laemmli, 1970) of purified axial filaments from $10^{9}$ bacteria, the band corresponding to the $37 \mathrm{kDa}$ polypeptide was located by staining the outside edges of a slab gel with Coomassie blue. The band was cut out, frozen in liquid nitrogen and pulverized with a glass rod. It was resuspended in $500 \mu \mathrm{l}$ PBS, mixed with an equal volume of Freund's adjuvant and $100 \mu$ injected i.p. as above.

Hyperimmune rabbit syphilitic sera (hRSS) were prepared as previously described (Bailey et al., 1985).

Hybridomas. Mab-secreting cell lines were produced and isolated essentially as described by Bailey et al. (1987). Washed spleen cells from immunized mice were combined at a ratio of $4: 1$ with NS-1 myeloma cells (Flow) (Kohler \& Milstein, 1975) and fused with polyethylene glycol 1450 (BRL). Cells were maintained in 96-well plates and Mab-producing hybridomas were detected by indirect ELISA or dot-blot ELISA.

ELISA. Antibody-secreting parent hybridomas were initially selected by ELISA. Wells of EIA plates (Nunc I, Gibco) were coated overnight at $4{ }^{\circ} \mathrm{C}$ with $100 \mu \mathrm{l}$ purified, washed and sonicated $T$. pallidum cells diluted $(5 \times$ $10^{7} \mathrm{ml}^{-1}$ ) in carbonate/bicarbonate buffer (Voller et al., 1979). Individual supernatants were sampled, and $50 \mu \mathrm{l}$ added to $50 \mu$ l double-strength PAT (PAT is $0.1 \%$, w/v, BSA, $0.1 \%$, w/v, Tween 20 in PBS) and allowed to react with the coated solid phase for $1 \mathrm{~h}$ at room temperature. After washing five times in PBS, $100 \mu \mathrm{l}$ rabbit anti-mouse immunoglobulin conjugated to horseradish peroxidase (Dako) diluted 1 in 1500 in PAT was added to each well and left to react for a further $1.5 \mathrm{~h}$. The substrate, o-phenylenediamine $\left(40 \mu \mathrm{g} \mathrm{ml}^{-1}, 0.04 \% \mathrm{H}_{2} \mathrm{O}_{2}\right)$ in citrate/phosphate buffer $\mathrm{pH} 5.0$ (Voller et al., 1979) was applied to each well of the washed plate and those wells containing antibody were identified colorimetrically. As the intention was to isolate Mabs specific to the axial filament polypeptides, an additional immunoassay was developed which required minute quantities of antigen and allowed for the screening of hundreds of supernatants.

Dot-blot ELISA. Using a nitrocellulose membrane (NCM) as the solid phase, $1 \mu \mathrm{l}$ volumes of purified, sonicated axial filament preparations (containing $10 \mathrm{ng}$ protein as estimated by the Lowry method) were spotted evenly onto the membrane at marked positions; duplicate areas were coated with the same amount of sonicated whole $T$. pallidum. After air drying for 60 min the NCM was blocked with 3\% BSA, 0.1\% Tween 20 in PBS for $1 \mathrm{~h}$, washed twice in PBS and placed on top of a wad of filter paper (Whatman 3MM) soaked in PAT. To each marked area of $1 \mathrm{~cm}^{2}$, containing the antigen preparations, was applied 2-3 $\mu \mathrm{l}$ ELISA-positive hybridoma supernatant. The filters were left for $\mathrm{l} \mathrm{h}$ at room temperature without shaking and then copiously washed in PBS. Rabbit anti-mouse immunoglobulin conjugated to alkaline phosphatase (Sigma) diluted 1 in 2000 in PAT was allowed to react with the filters for $2 \mathrm{~h}$ at room temperature on an orbital shaker, and after further washing, specific anti-axial filament antibody-containing supernatants were identified with the fast red/naphthol ASMX phosphate substrate (Sigma) described by O'Connor \& Ashman (1982). Hybridomas were cloned twice by limiting dilution onto splenic feeder 
Table 1. Immunization protocols in female Balb/c for the production of anti-T. pallidum axial filament Mabs

Mice were primed (day 0) with antigen delivered in Freund's complete adjuvant and boosted with antigen in Freund's incomplete adjuvant. Antigen preparations : soni. cells, sonicated whole $T$. pallidum cells; AF, sonicated purified axial filaments; $37 \mathrm{kDa}, 60 \mathrm{kDa}, 37$ and $60 \mathrm{kDa}$ polypeptides eluted from SDS-PAGE gels

Type of i.p. injection on day
Mab code

C

H, I

J

$\mathrm{K}, \mathbf{S}$

L, N

$\mathbf{M}$

0
Soni. cells
AF
Live Tp
Soni. cells
$37 \mathrm{kDa}$
$60 \mathrm{kDa}$

- Intravenous boost with antigen diluted in PBS $4 \mathrm{~d}$ before fusion. The time (d) after the first injection is shown in parentheses.

cells $\left(5 \times 10^{6}\right.$ per well in 96 -well plates $)$ and the specificity of the Mab was determined by Western blotting. Mabs were produced in quantity by cell culture.

$S D S-P A G E$ and immunoblotting. Linear gradient acrylamide $(8-20 \%, \mathrm{w} / \mathrm{v})$ or continuous $11 \%(\mathrm{w} / \mathrm{v})$ gels were run with buffers and conditions essentially as described by Laemmli (1970). Polypeptides were either stained with Coomassie blue (PAGE 83, BDH) or transferred electrophoretically to NCM $(0.45 \mu \mathrm{m}$, Anderman) according to the method of Towbin et al. (1979). After transfer, the NCMs were blocked as described above for the dot-blot assay and reacted with sera or Mab diluted in PAT. Gels were routinely loaded with bacterial suspensions of $2 \times$ $10^{7}$ organisms in $20 \mu \mathrm{l}$ sample buffer, the suspensions first solubilized by boiling for $5 \mathrm{~min}$, or with $5 \mu \mathrm{g}$ axial filament preparation in sample buffer, also boiled as above. The molecular masses of the polypeptides were determined by the method of Weber \& Osborn (1981) with molecular mass standards from Bio-Rad. Values presented in the figures refer to the known molecular masses of treponemal polypeptides (Penn et al., 1986). Those polypeptides reactive with antibody were detected by the immunoperoxidase technique. Immunoglobulin class specificity was determined by double immunodiffusion in $1 \%(\mathrm{w} / \mathrm{v})$ agarose in $0.08 \mathrm{M}$-barbitone buffer $\mathrm{pH} 8.2$, using anti-mouse sub-class antisera supplied by Dr D. Catty, Department of Immunology, University of Birmingham, UK.

Immunogold electron microscopy. After removal of the outer membrane from purified treponemes with Triton X100 , sera (1/50 dilution) or Mabs (1/10 dilution) were allowed to react at $37^{\circ} \mathrm{C}$ for $1 \mathrm{~h}$ with the released axial filaments in suspension. After washing in PBS, the antibody/treponemal suspension was applied to Formvarcoated copper grids. Non-specific binding sites were blocked with $3 \%(w / v)$ BSA in PBS and the samples were then reacted with rabbit anti-mouse antibody gold conjugates (Janssen) as above. After washing, samples were negatively stained with $3 \%(\mathrm{w} / \mathrm{v})$ phosphotungstic acid pH 7.2 and viewed with a Philips 201 electron microscope.

T. pallidum immobilization test. Specific sera and Mabs (the latter concentrated 40-fold by ammonium sulphate precipitation) were assessed for their ability to immobilize $T$. pallidum in vitro by a modification of the method of Nelson \& Mayer (1949) as described by Bailey et al. (1987).

\section{RESULTS}

\section{Antibody response}

Mice, when injected with live organisms or immunized with azide-killed bacteria included in Freund's adjuvant to induce a hyperimmune state, responded poorly to those antigens comprising the axial filament of $T$. pallidum (Fig. 1) when compared with the response observed with rabbit or human syphilitic sera (Fig. 2). Sonication of the organism prior to injection did not enhance the stimulation of anti-37 kDa polypeptide antibody in Balb/c mice (arrow, Fig. 1, II). Repeated injections of live organisms produced a very weak and restricted range of antibody to $T$. pallidum. However, purified axial filament (a particulate antigen preparation), either in non-immunized mice or in mice previously immunized with either live or dead whole cells, was capable of producing a good specific response. Further, the $37 \mathrm{kDa}$ polypeptide isolated by SDS- 


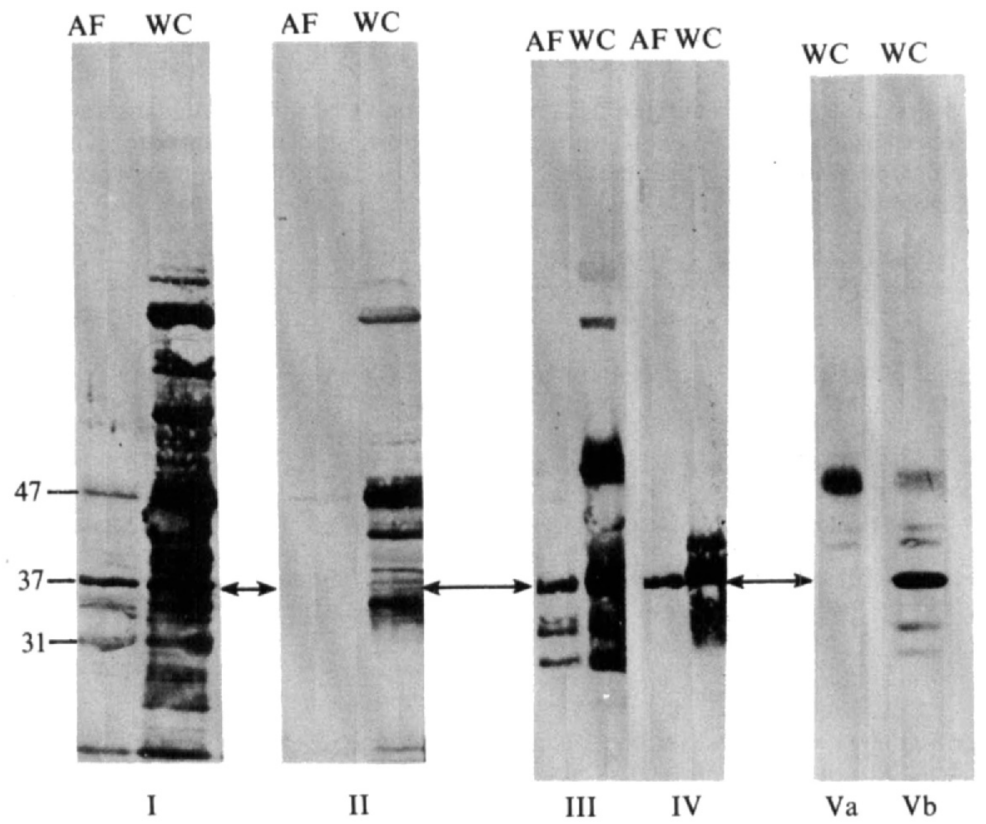

Fig. 1. Immunoblot analysis of purified $T$. pallidum axial filaments (AF) and whole $T$. pallidum cells (WC) run on an $11 \%$ SDS-PAGE gel and reacted with 1 in 100 dilutions of sera prepared as indicated below. Mouse sera were taken $10 \mathrm{~d}$ after the final injection. I, hRSS. II, Sera from mice immunized with $10^{8}$ sonicated dead bacteria included in Freund's adjuvant (four i.p. injections of $0.1 \mathrm{ml}$ at $14 \mathrm{~d}$ intervals). III, Sera from mice immunized as in II and boosted on days 56 and 68, with purified $T$. pallidum axial filaments in adjuvant. IV, Sera from mice immunized with the $37 \mathrm{kDa}$ antigen, extracted from SDS-PAGE gels, included in adjuvant (four i.p. injections of $0.1 \mathrm{ml}$ at $14 \mathrm{~d}$ intervals). Va, Sera from mice injected with $10^{8}$ live treponemes diluted in extraction buffer (four i.p. injections of $0.1 \mathrm{ml}$ at $14 \mathrm{~d}$ intervals). $\mathrm{Vb}$, Sera from mice injected as in $\mathrm{Va}$ and boosted on days 56 and 68, with purified $T$. pallidum axial filaments in adjuvant. Molecular masses (kDa) of known $T$. pallidum polypeptides are shown.

PAGE was also strongly antigenic in mice. Fig. 1 (III) shows the antibody response of immunized mice given booster injections of purified axial filament preparations. This demonstrates that this structure is composed of at least four clearly distinguishable antigens, of $37,34,33.5$ and $31.5 \mathrm{kDa}$. Additional antigens were recognized when anti-axial filament serum was reacted by immunoblotting against whole $T$. pallidum. These additional antigens are highly antigenic membrane-associated components (47, 44 and $32 \mathrm{kDa}$ ) (unpublished observations) present as contaminants in purified axial filament preparations in sufficient quantity to elicit an antibody response detectable by immunoblotting with whole $T$. pallidum as the antigen (Fig. 3 ). Cross-reacting antigens present in both $T$. phagedenis $(38 \cdot 5,35$ and $33 \mathrm{kDa}$ ) and $T$. hyodysenteriae $(33 \mathrm{kDa})$ were identified by immunoblotting whole organisms of these species with the antisera to $T$. pallidum axial filaments (Fig. 3), and additional cross-reacting polypeptides were demonstrated with hRSS (Fig. 4).

\section{Identification of Mabs against axial filament polypeptides}

By dot-blot assay on ELISA-positive hybridoma supernatants a number of cell lines secreting antibody specific to the axial filament structure were identified. This technique allows for the minimal use of precious antigen from a sub-fraction of $T$.pallidum to isolate desired antibody. By immunoblotting (Fig. 4), a range of Mabs (e.g. Mabs Cc9, HC2, IB8, K3D4) were selected which reacted with the $37 \mathrm{kDa}$ major polypeptide described by Penn et al. (1985a). Mabs which reacted with the other components, the $31.5 \mathrm{kDa}$ polypeptide (JD11), and Mabs that reacted with both the 31.5 and the $33.5 \mathrm{kDa}$ polypeptides (Sc12) were also isolated (data not shown). A 


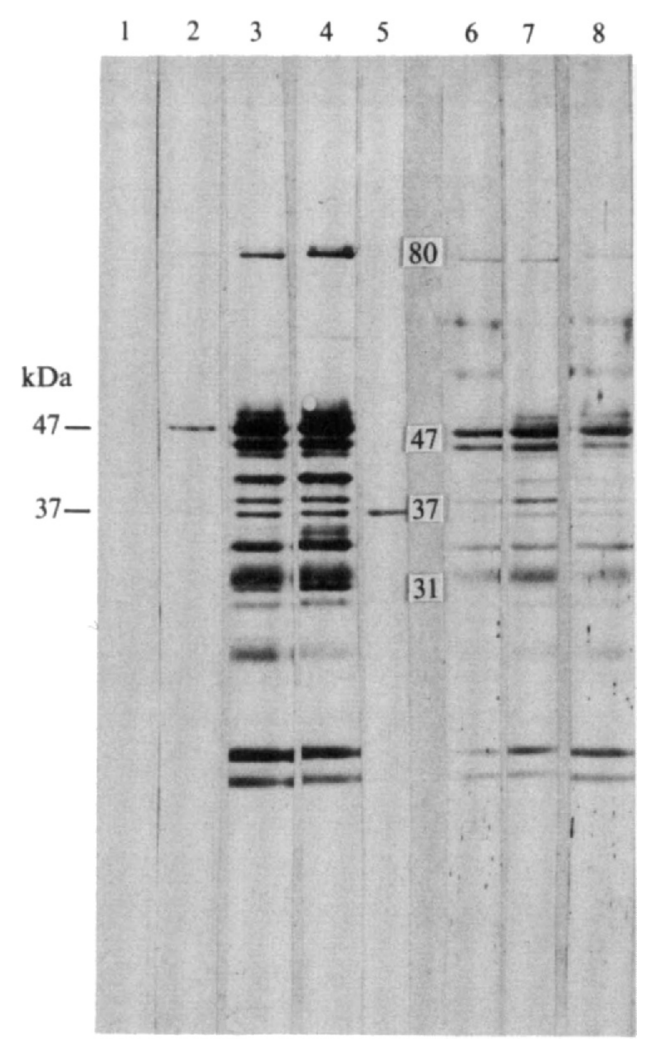

Fig. 2. Immunoblot analysis of whole cells of $T$. pallidum run on an 8-20\% SDS-PAGE gel and reacted with the following. 1-4, Rabbit sera (all 1 in 100): 1, normal ; 10 d p.i.; 3, convalescent (6 months p.i.); 4, hyperimmune. 5, Anti-37 kDa Mab Cc9 (1 in 50). 6-8, Three different samples of late primary/secondary human syphilitic sera ( 1 in 50$)$. Molecular masses (kDa) of known $T$. pallidum polypeptides are shown.

Mab (K2F1) which recognized antigenic sites on the $34,33.5$ and $31.5 \mathrm{kDa}$ polypeptides was obtained. Further Mabs derived from the fusions L (LB12), M (ME2) and N (NG4) (Table 1) were ELISA- and dot-blot-positive but reacted only very weakly at 1 in 5 dilutions by Western blotting (data not presented); surprisingly, these Mabs were obtained from mice immunized with denatured polypeptide eluted from SDS-PAGE gels and were exposed to native antigen only in the final boost before fusion. A number of fusions following different immunization protocols were done in order to stimulate the generation of a range of anti-37 kDa Mabs useful both for structural analysis and in diagnosis.

\section{Antigenic relatedness between spirochaetes}

Sera and Mabs were assessed for their ability to react with the polypeptide antigens of treponemes other than $T$. pallidum (Nichols). The analysis was done by immunoblotting. hRSS contained cross-reactive antibody to both $T$. phagedenis and $T$. hyodysenteriae (Fig. 4$)$. At least six strongly reactive bands were identified in $T$. phagedenis, three of which are associated with the axial filament of this organism $(33,35$ and $38.5 \mathrm{kDa}$ ). The Mab IB8 (IgG 1) reacted very strongly not only with the major $37 \mathrm{kDa}$ polypeptide of $T$. pallidum but also with the equivalent polypeptide in $T$. phagedenis $(38.5 \mathrm{kDa})$. Cross-reactivity with $T$. hyodysenteriae was also observed with hRSS and Mabs. Mab Cc9 (IgM against $37 \mathrm{kDa}$ polypeptide) reacted only weakly with a band of $35.5 \mathrm{kDa}$ in $T$. hyodysenteriae. The same polypeptide was recognized by both the hRSS and the anti-axial-filament sera; this polypeptide is considered to be the major axial 


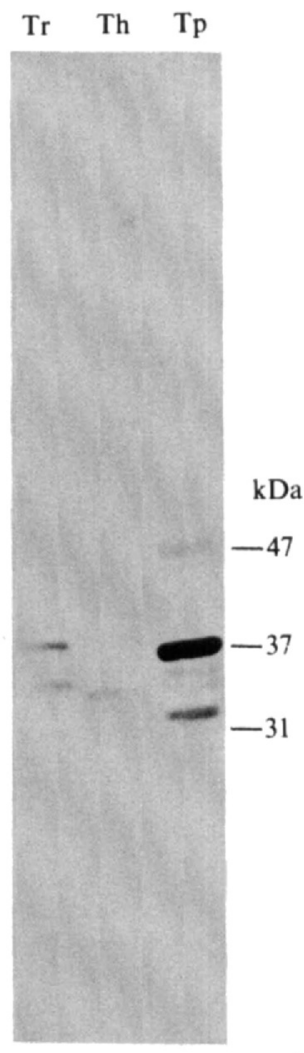

Fig. 3

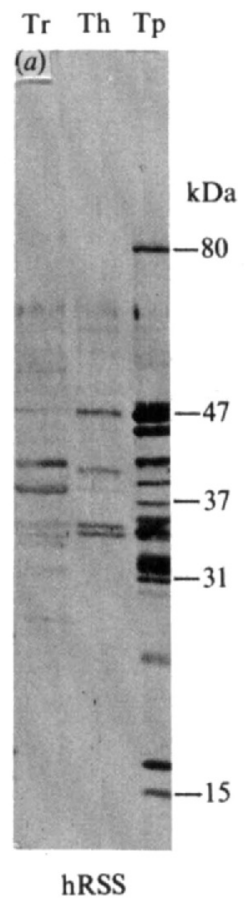

Fig. 4
Th Tr Tp Tp Tp Tp Tp Tr Th

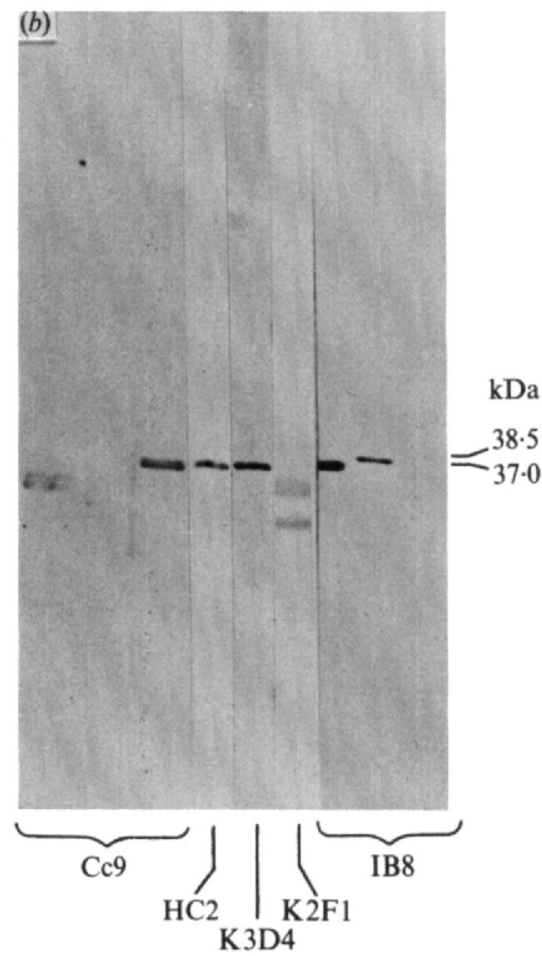

Fig. 3. Immunoblot analysis of whole cells of $T$. phagedenis $(\mathrm{Tr}), T$. hyodysenteriae $(\mathrm{Th})$ and $T$. pallidum (Tp) reacted with 1 in 100 dilutions of mouse anti- $T$. pallidum axial filament sera.

Fig. 4. Comparative immunoblots of whole cells of $T$. phagedenis $(\mathrm{Tr}), T$. hyodysenteriae $(\mathrm{Th})$ and $T$. pallidum (Tp) reacted with: (a) 1 in 100 dilution of hRSS; $(b) 1$ in 20 dilution of monoclonal antibody supernatants, showing specificity of the Mabs. Negative results are not included. Molecular masses (kDa) of known $T$. pallidum polypeptides are shown.

filament polypeptide of $T$. hyodysenteriae since Coomassie-blue-stained gels containing purified $T$. hyodysenteriae axial filaments (provided by $\operatorname{Dr} \mathrm{R}$. M. Lemcke) contained a predominant band of this size (unpublished observations). The remainder of the Mabs reported here were highly specific for $T$. pallidum and even at high concentrations ( 1 in 5 dilution) did not cross-react with the other treponemal species investigated. The diversity of antigens recognized by the Mabs possibly reflects the commonality and conserved nature of the axial filament antigens within the genus Treponema and demonstrates, especially with $\mathrm{K} 2 \mathrm{~F} 1$, the presence of shared antibodybinding sites between polypeptides of the $T$. pallidum axial filament.

\section{Immunogold electron microscopy}

The anti-37kDa Mab Cc9 was strongly reactive with the surface of the axial filament of $T$. pallidum, unequivocally demonstrating the location of this polypeptide. The other Mabs against the $37 \mathrm{kDa}$ antigen showed variability in their reactivity by immunogold techniques, 

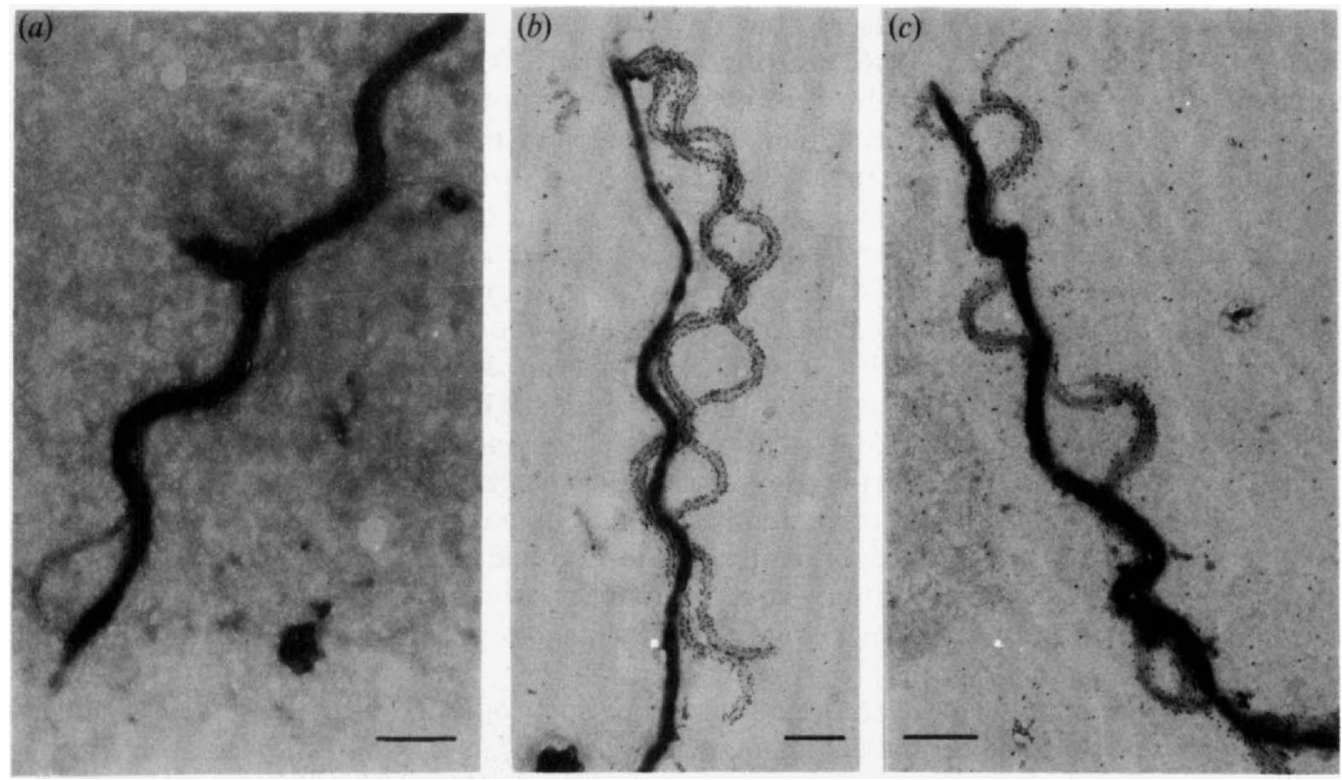

Fig. 5. Immunogold electron microscopy of Mabs reacted with the axial filaments of $T$. pallidum (the outer membrane was removed by detergent treatment). (a) NS-1 supernatant control; (b) Mab Cc9; (c) Mab K3D4. Bars, 0.2 $\mu \mathrm{m}$.

underlining in the cross-reactivity studies that a diverse range of Mabs against many epitopes had been generated. Cc9 and K3D4 were the most avid immunogold-reactive Mabs (Fig. 5), suggesting that they were directed against external epitopes on the surface of the endoflagella. In a small percentage of the population a degree of heterogeneity of binding with the Cc9 Mab was observed, which has prompted the further investigation of the composition of the axial filament to confirm that the $37 \mathrm{kDa}$ polypeptide is indeed the sheath protein which surrounds the core structure constructed from the remaining polypeptides (Cockayne et al., 1987). None of the other Mabs against the other polypeptides were immunogold-positive when reacted with intact axial filament, and therefore the location of these polypeptides as axial filament components could not be confirmed by the methods employed.

\section{T. pallidum immobilization}

All the Mabs tested in the immobilization assay were unable to immobilize T. pallidum in vitro. The periplasmic location of the axial filaments could explain the lack of reactivity, as the Mabs would be excluded from binding in intact organisms. The polyclonal sera against the purified axial filament were not tested as they contained antibody against non-axial-filament polypeptides. One of the contaminating antibody specificities was directed against the $44 \mathrm{kDa}$ antigen, which has been shown to elicit immobilizing antibody (Bailey et al., 1987).

\section{DISCUSSION}

A wide variety of anti- $T$. pallidum antibodies are present in the sera of infected human patients or experimentally infected rabbits (Fig. 2). Certain polypeptides have been investigated and identified, allowing a logical and more accurate assessment of the role of particular antigens in the development of both immunity and humoral responses (Penn et al., 1986). A number of immunodominant antigens have been identified which elicit the stimulation of antibody to specific antigens early in infection. The most dominant of these antigens are the $37 \mathrm{kDa}$ axial filament polypeptide (Penn et al., 1985a) and the $47 \mathrm{kDa}$ outer-membrane-associated polypeptide (Penn et al., 1985b). Mice however, when injected with live $T$. pallidum do not 
develop any clinical signs of disease but do react immunologically following contact with antigen. Saunders \& Folds (1986) recently demonstrated the development of a progressive immune response to treponemal antigens in mice injected with live treponemes but not in those injected with dead ones, suggesting that this pathogen is able to survive and multiply in the mouse, but to a lesser extent than in the rabbit. In this work we have shown that mice apparently do not respond as well to $T$. pallidum antigens as do rabbits, eliciting antibody to only a limited range of antigens. When $10^{8}$ live treponemes were injected subcutaneously or intraperitoneally into mice only very weak ELISA titres were recorded (unpublished observations) with the predominant antibody detectable being directed against the $47 \mathrm{kDa}$ antigen (Fig. 1, Va). This poor response has been described previously (McLeod \& Magnuson, 1951; Ohta, 1972; Robertson et al., 1982), indicating that a large inoculum of live organisms must be repeatedly delivered in order to evoke even a low-titre response. The inclusion of treponemes in adjuvant enhanced the antibody titre, and the sonication of the bacterial suspension increased the range of antibodies stimulated. However, we found that hybridomas generated from mice immunized with unmodified $T$. pallidum predominantly secreted antibody to the $47 \mathrm{kDa}$ antigen regardless of the route or rate of inoculation. Also, by immunization protocols using unfractionated bacteria as the antigen source we were virtually unable to stimulate specific anti-37 $\mathrm{kDa}$ antibody (Fig. 1, II).

The fractionation of the bacteria and the use of a variety of immunization protocols (Table 1) stimulated antibody specific to axial filament antigens (Fig. 1, III, IV, Vb), indicating that the polypeptides were indeed highly antigenic in mice but were in some way masked when delivered in the form of whole or sonicated T. pallidum cells. Table 1 outlines the immunization schedules adopted from which anti-37 kDa Mabs were selected. The Mabs that reacted most strongly by immunogold electron microscopy were generated from mice immunized only with native antigen (i.e. Cc9 and K3D4), although not all the Mabs produced with these immunization schedules were immunogold-reactive. The use of denatured $37 \mathrm{kDa}$ polypeptide as an antigen was very effective in stimulating mouse antibody (Fig. 1, IV), but the Mabs produced were only very weakly immunoblot-positive, demonstrating that additional epitopes are present on this polypeptide which are not detected by ELISA or the dot-blot ELISA, which only presents native epitopes. This observation is supported by the Mabs generated following fusion M (i.e. ME2), in which mice were immunized with the $60 \mathrm{kDa}$ polypeptide cut from gels and boosted once only with purified axial filaments (Table 1). The $60 \mathrm{kDa}$ polypeptide has been identified as the common bacterial antigen (Hindersson et al., 1984) and is not a component of the axial filament. Thus the Mabs produced that reacted by dot-blot with the axial filament resulted from the final boost and not from the initial immunization protocol. The use of immunization schedules including preparations of purified axial filaments or their constituent polypeptides is considered essential for the production of Mabs to this structure.

From the studies done with the Mabs against the axial filament of $T$. pallidum we have been able to identify a number of component polypeptides and by immunogold labelling unequivocally confirm the observations of Penn et al. (1985a) that the $37 \mathrm{kDa}$ polypeptide is the major component of this structure. The range of Mabs produced defines a number of different epitopes as determined by the diversity observed in their cross-reactivity with other treponemes, and differential reactivity by gold labelling and immunoblotting. These findings indicate that the denatured polypeptide is strongly antigenic and that there are a number of internalized antibody-binding sites on the native molecule; it is therefore essential that selective immunization protocols be adopted in order to generate Mabs which bind to epitopes on the surface or within the axial filament. The combination of the appearance of strong antibody responses to the $37 \mathrm{kDa}$ polypeptide in both infected rabbits and man, and the demonstration that a variety of epitopes are detectable on this molecule, suggests the usefulness of these reagents in the immunodiagnosis of syphilis. 


\section{REFERENCES}

Bailey, M. J., Cockayne, A. \& Penn, C. W. (1985). Evidence for the presence of lipopolysaccharide in Treponema phagedenis (biotype Reiterii) but not in Treponema pallidum (Nichols). FEMS Microbiology Letters 27, 117-121.

Bailey, M. J., Cockayne, A. \& Penn, C. W. (1987). Monoclonal antibodies directed against surfaceassociated polypeptides of Treponema pallidum define a biologically active antigen. Journal of General Microbiology 133, 1793-1803.

Bharrier, M. \& Allis, D. (1974). Purification and characterization of axial filaments from Treponema phagedenis biotype Reiterii (the Reiter treponeme). Journal of Bacteriology 120, 1434-1441.

Cockayne, A., Balley, M. J. \& Penn, C. W. (1987). Analysis of sheath and core structures of the axial filament of Treponema pallidum. Journal of General Microbiology 133, 1397-1407.

Hanff, P. A., Fehniger, T. E., Miller, J. N. \& LOVETT, M. A. (1982). Humoral immune response in human syphilis to polypeptides of Treponema pallidum. Journal of Immunology 129, 1287-1291.

HaNfF, P. A., Bishop, N. H., Miller, J. N. \& Lovett, M. A. (1983). Humoral immune response in experimental syphilis to polypeptides of Treponema pallidum. Journal of Immunology 131, 1973-1977.

Hindersson, P., Petersen, C. S., Pedersen, N. S., HoRBY, N. \& AXELSEN, N. H. (1984). Immunological cross reactivity between antigen Tp4 of $T$. pallidum and an antigen common to a wide range of bacteria. Acta pathologica, microbiologica et immunologica scandinavica 92, 183-188.

Hindersson, P., Sand-Pedersen, C. \& Axelsen, N. H. (1985). Purified flagella from Treponema phagedenis biotype Reiter does not induce protective immunity against experimental syphilis in rabbits. Sexually Transmitted Diseases 12, 124-127.

Kohler, G. \& Milstein, C. (1975). Continuous cultures of fused cells secreting antibody of predetermined specificity. Nature, London 256, 495-497.

LAEMMLI, U. K. (1970). Cleavage of structural proteins during the assembly of the head of bacteriophage T4. Nature, London 227, 680-685.

LUKEHART, S. A., BAKER-ZANDER, S. A. \& GUBISH, E. R. JR (1982). Identification of Treponema pallidum antigens; comparison with a non-pathogenic treponeme. Journal of Immunology 129, 833-838.

MCLeod, C. P. \& Magnuson, H. J. (1951). Development of treponemal immobilizing antibodies in mice following injection of killed Treponema pallidum (Nichols strain). Journal of Venereal Diseases and Infections 32, 274-279.

Nell, E. E. \& Hardy, P. H. (1978). Counterimmunoelectrophoresis of Reiter treponeme axial filaments as a diagnosis test for syphilis. Journal of Clinical Microbiology 8, 148-152.

Nelson, R. A. \& MAYer, M. M. (1949). Immobilization of Treponema pallidum in vitro by antibody produced in syphilitic infection. Journal of Experimental Medicine 89, 369-373.
O'Connor, C. G. \& Ashman, L. K. (1982). Application of the nitrocellulose transfer technique and alkaline phosphatase conjugated anti-immunoglobulin for determination of the specificity of monoclonal antibodies to protein mixtures. Journal of Immunological Methods 54, 267-271.

OHTA, Y. (1972). Treponema pallidum antibodies in syphilitic mice as determined by immunofluorescence and passive haemagglutination techniques. Journal of Immunology 108, 921-926.

PenN, C. W. (1981). Avoidance of host defences by Treponema pallidum in situ and on extraction from infected rabbit testes. Journal of General Microbiology 126, 69-75.

PENN, C. W. (1983). The use of the rabbit as a model for syphilis infection. In Experimental Bacterial and Parasitic Infections, pp. 145-151. Edited by G. Keusch \& T. Wadstrom. Amsterdam: Elsevier Biomedical.

PenN, C. W. \& Rhodes, J. G. (1982). Surface associated antigens of Treponema pallidum concealed by an inert outer layer. Immunology 46, 9-16.

Penn, C. W., Bailey, M. J. \& Cockayne, A. (1985a). The axial filament antigen of Treponema pallidum. Immunology 54, 635-641.

Penn, C. W., Cockayne, A. \& Bailey, M. J. (1985b). The outer membrane of Treponema pallidum : biological significance and biochemical properties. Journal of General Microbiology 131, 2349-2357.

Penn, C. W., Bailey, M. J. \& Cockayne, A. (1986). Molecular and immunochemical analysis of Treponema pallidum. FEMS Microbiology Reviews 32, 139 148.

Robertson, S. M., Kettman, J. R., Miller, J. N. \& Norgard, M. V. (1982). Murine monoclonal antibodies specific for virulent Treponema pallidum (Nichols). Infection and Immunity 36, 1076-1085.

SAUNDERS, J. M. \& FoldS, J. D. (1986). Humoral response of the mouse to Treponema pallidum. Genitourinary Medicine 61, 221-229.

Strandberg-Pedersen, N., Axelsen, N. H. \& SandPedersen, C. (1981). Antigenic analysis of Treponema pallidum: cross reactions between individual antigens of $T$. pallidum and $T$. reiter. Scandinavian Journal of Immunology 13, 143-150.

Strandberg-Pedersen, N. S., Sand-Pedersen, C., VEJTORP, M. \& AXELSEN, N. H. (1982). Serodiagnosis of syphilis by an enzyme-linked immunosorbent assay for IgG antibodies against the Reiter treponeme flagellum. Scandinavian Journal of Immunology 15, 341-348.

Towbin, H., Staehelin, T. \& Gordon, J. (1979). Electrophoretic transfer of proteins from polyacrylamide gels to nitrocellulose sheets: procedure and some applications. Proceedings of the National Academy of Sciences of the United States of America 76, $4350-4354$.

Voller, A., Bidwell, D. E. \& Bartlett, A. (1979). ELISA, a Guide with Abstracts of Microplate Applications. Dynatech Publications. 